\title{
CREATIVE MULTIPLICITIES: Urban Morphologies of Creative Clustering
}

\author{
Stephen Wood \& Kim Dovey
}

\begin{abstract}
Research on creative clusters or milieus has established the importance of urban diversity for the embedding of concentrated creative production in certain neighbourhoods of the city - sites that are often characterized as having a creative 'buzz' or 'atmosphere'. This paper seeks to ground such a proposition empirically in characteristics of urban morphology through a study of creative clustering in Sydney and Melbourne. Relations between creative production and urban morphology are mapped and analysed at multiple scales within a framework of assemblage theory. These clusters are shown to be characterized by synergies that emerge from a multiplicity of diversities - a 'mix of mixes' that link socio-economic, functional and morphological factors. The morphology embodies a mix of lot sizes, building ages, types, and public/private interfaces. These are linked to a multiplicity of functions (production, exchange, reproduction, recreation), firms (start-up and established), rents and people. The paper concludes with some prospects for rethinking questions of urban diversity as multiplicity.
\end{abstract}

\section{INTRODUCTION}

There is now a huge literature on the rise of the creative economy, creative classes and the clustering of creative industries, both in particular cities and particular neighbourhoods within those cities. While most of this discourse has been focused at the geographic scale of inter-city competition,

demographics and policy, it has long been clear that creative industries do not locate randomly within cities and are sensitive to 'qualities of place' at the neighbourhood scale. While the importance of quality of place to creative clustering is repeatedly acknowledged, the associated micro-spatialities and morphologies remain under-researched. Many of the descriptive concepts, such as 'buzz' and 'atmosphere', are relatively fuzzy, difficult to codify (Trip 2007), and often subject to overgeneralisation and romanticism (Rantisi \& Leslie 2006; Mommas 2004). The issue is confounded by a widespread conflation of creative cities with creative clusters within them. While most of the discourse on policy involves inter-city competition, that on quality of place, buzz or atmosphere tends to focus on the scale of the district or neighbourhood. While creative clustering is clearly a multi-scalar phenomenon the focus in this article is on smaller scales where the density and diversity of face-to-face interactions are seen as central. In what follows, this paper considers key dimensions of the literature on creative clustering, before exploring the morphological, functional and socio-economic mixes associated with key creative clusters in two Australian cities. ${ }^{1}$

\section{CREATIVE CLUSTERING}

\section{Something 'in the air': Economics of clustering}

The clustering of particular trades, services and industries in certain urban neighbourhoods is as old as cities. In the late $19^{\text {th }}$ Century Marshall (1890) argued that the economic advantages of industry clustering included a ready supply of labour, shorter distances along the production supply chain and the collective attraction of multiple competitors delivering a large customer base. He was also the first to note what he termed something 'in the air' - an ethereal quality or atmosphere that could not be quantified - a spillover of 'tacit knowledge' that relied on face-to-face contact. While Marshall focused on knowledge transfer between firms within an industry, Jacobs (1969) later suggested that innovation relies on spillovers between different industries and fields.

There are two different agglomerative effects at work here - density and network effects. Density shortens the distances and increases the ease of face-to-face meetings and the frequency of ad-hoc encounters in public space. The economic value of the density effect comes from both the reduction of distance and from the spillover of tacit knowledge created. The network effect relates to the way the value of each node in a network increases with the number of nodes in the network (Katz \& Shapiro, 1985). Each new node (artist, firm, gallery, studio, music venue) adds value to all of the other 
nodes of that network. The network effect is not an economy of scale (bringing down costs as the scale of production increases) but an added value due to network interactivity. Network effects can diminish with density as congestion sets in (Liebowicz \& Margolis 1994).

Both density and network effects are argued to be particularly important in creative industries and knowledge based economies because of the crucial central role of innovation and flows of ideas. Storper and Venables (2004: 351) argue that: 'Face to face is particularly important in environments where information is imperfect, rapidly changing, and not easily codified, key features of many creative activities'. While such clustering is identified with open networks and 'weak ties' rather than enclosed forms of social capital, it is also seen as a place where relations of trust develop that enable both enduring business partnerships and an economy of local 'street rates'. The need to anticipate trends means that immersion in the face-to-face networks of a creative field is seen to create an environment where it is safer to take risks because they are 'socialized' through the network - safety in a crowd (Rantisi \& Leslie 2006).

\section{'Buzz' and 'Atmosphere': Creative clusters}

Where Marshall found something 'in the air' in trade clusters, a certain 'buzz' or 'atmosphere' is said to permeate creative clusters (Currid \& Williams 2010; Storper \& Venables 2004; Drake 2003; see also Bohme 1993, 1998); creative neighbourhoods are often distinguished by their 'look and feel', 'flavour' or 'character' and 'authenticity' (Brown \& Meczynski 2009, Ho 2009; Hutton 2006; Helbrecht 2004). They are conceived as incubators of innovation (Peck 2005), 'seething with the interplay of cultures and ideas' (Florida 2002: 227). Business and social networks are seen as open to newcomers, tolerant of difference and attractive to young talent, what Florida (2002: 304) calls 'plug and play' communities with a strong work/life connection. They are 'sticky' places in the sense that creative firms become economically attached to the cluster (Markussen 1996; Gertler 2003). They are described as having a sense of 'intimacy' or 'cosiness' (Hutton 2006), with friendly pedestrian streetscapes, easy walkability and the 'feel' of an urban village. The 'character' is often described as informal, bohemian or even derelict and dingy (Hutton 2004; Lloyd 2002; Ho 2006). The importance to creative clusters of these, and similar, 'qualities of place' are repeatedly flagged, yet rarely grounded empirically. In so far as their genesis remains unexplored, it can be a short step from naming such qualities to producing and marketing them through superficial streetscape upgrades, leading in turn to criticisms of design-led regeneration (Bell and Jayne 2003; Evans 2003, Catungal et al 2009).

To unpack these issues further, this paper adopts two key emphases that are uncommon in the literature on creative cities. The first of these is a focus on the smaller scale of neighbourhood, district, quarter, milieu or cluster. These terms are neither interchangeable nor innocent. 'Milieu' suggests surroundings and is person-centred; it has the advantage of being inherently socio-spatial but the disadvantage of suggesting a relatively large scale. 'District' and 'quarter' both suggest governance of spatial territory. The term 'cluster' is used here because it is both noun and verb; a socio-spatial assemblage of people, buildings and activities without any necessary centre, boundary or scale.

The second emphasis is a focus on urban morphologies - on the physical or formal structures of places - and ways in which these intersect with socio-spatial flows to nurture production of the aforementioned qualities of place that are linked to creative clusters. To date, research on the role of urban morphology in creative clustering has been limited (Rantisi 2006). It is clear that creative production has a certain synergy with post-industrial building types such as warehouses and factories. Hutton (2006) argues that such buildings are often valued for their links to earlier forms of production - what he terms an 'embedded truth' or 'integrity'. Industrial buildings were designed to be flexible shells and this flexibility is highly valued for creative production This is an advantage that extends to a range of pre-modern building types such as shophouses (Ho 2009). Detailed mapping of creative enterprises is relatively rare and where it is done is generally limited to constellations that indicate the extent of clustering but little more (Currid and Williams 2010; Evans and Foord 2007; Hutton 2004; Newman and Smith 2000). 
A key precedent for this line of inquiry is the work of Jacobs (1961) whose primary fieldwork was undertaken within the creative cluster of Greenwich Village focusing on formal and functional diversity. Her call for the retention of old buildings was based upon the mix of old and new; on the ways an architectural mix embodies diverse expressions of identity as well as diverse building types and sizes with diverse levels of usefulness and therefore diverse rental value. Her discussion of mixed-use has been fundamental to understanding the value of mixing different activities with different people, rhythms and synergies. Jacobs also identified the key issues of permeability and density, not as forms of diversity but as key conditions for intensive face-to-face urban interaction. Her theory of the selfdestruction of diversity has much in common with later theories of gentrification.

While Jacobs' account of urban diversity is seminal, it is perhaps too simple and too easily adopted into top-down urban design formulae - whether 'mixed-use' or 'creative city' policy. In this context, it might be usefully supplemented by theories of assemblage linked to the work of Deleuze and Guattari (1987). A key aspect of such an approach is to focus on connections and flows rather than things in themselves which are seen as products of connections. Assemblage is both noun and verb with a focus on processes of emergence and becoming more than fixed identities that are seen as outcomes of connection and flow. Assemblage theory provides an intellectual framework for rethinking the notion of urban diversity as multiplicity. From such a view creative clustering is a form of socio-spatial assemblage where people and spatial context are mutually constituted (DeLanda 2006). What we call 'place', 'character', 'buzz' and 'atmosphere' are emergent effects of this assemblage, socio-spatial phenomena that slip easily between social and formal characteristics (Dovey et al 2009). The Deleuzian question is not about what they mean but how they work. This is not a search for essential truths or cause/effect relations - urban morphology does not cause creative clustering any more than creativity causes the morphology. An assemblage approach is anti-reductionist - resisting reduction to the economic, social or environmental; rather it offers a framework for understandings that incorporate the phenomenology of everyday life (buzz, look and feel, character) as well as representational issues (symbolic capital, branding) and the materiality and morphology of the city (building form, spatial structure).

\section{Mapping Creative Clusters}

There are many difficulties in researching these dimensions of creative clustering, especially concerning categorisations. It is now clear that there are many different kinds of creative cluster. Evans (2009) makes a key distinction between cultural quarters (where heritage tourism, place branding and consumption are strong) and creative industry quarters which are more production oriented and occupied by a broader knowledge economy. He also distinguishes between vertically integrated industry clusters (such as specialized art or film districts) and the more diverse and horizontally integrated districts spanning the different arts. The clusters studied in this paper span across these categories.

There can be no universal criteria for defining a creative industry (Banks and O'Connor 2009) although such definitions generally extend beyond the visual and performing arts to include new media, design, furniture and fashion. There is no clear boundary between knowledge intensive and creative industries (Hutton 2009) and some researchers would include science, technology and finance precincts (Florida 2005). Creativity is not limited to art and design is not limited to form. Creative firms span different market sectors from subcultural bohemian to established corporations (Indergaard 2009). Clusters often mix production, exchange, consumption and recreation without clear divisions, and the life/work and production/consumption connections may be crucial (Chapain \& Comunian 2009).

When difficulties of categorisation and codification have been encountered throughout this project, we have come to recognise them as the very problem we seek to understand. It was Koestler (1964: 356) who first defined creativity as a connection or 'bi-sociation' between two previously unrelated planes of reference; the both/and condition is fundamental to creativity. Nevertheless, for the purpose of mapping morphological aspects of creative clustering it was necessary to develop codification protocols. Four categories of creative industry were used: visual arts (studios, galleries); performing arts (live music, theatre); design (architecture, fashion, graphics); and media (film, new media). ${ }^{2}$ These should not be construed as necessarily separate or essential; the code is just a conceptual framework 
for interrogating the city. In the maps that follow, divisions between ingredients are somewhat arbitrary as they must be - many built-form variables may be categorised in an infinite number of ways. As Bateson (2000: 457-9) puts it:

We know the territory does not get onto the map... Differences are the things that get onto a map. But what is a difference? ...the word 'idea', in its most elementary sense, is synonymous with 'difference'... there is an infinite number of differences... Of this infinitude, we select a very limited number which become information. In fact, what we mean by information - the elementary unit of information - is a difference which makes a difference.

In other words, mapping is a production of ideas; the maps are as conceptual as they are illustrative. Out of the infinitude of differences that comprise the city, some 'differences that make a difference' are selected and coded. The practical limit is found in the experience of map reading - too much differentiation causes an image wherein patterns are too complex to read, hence a loss of information. While the maps are representations of empirical spatial facts they are also forms of intellectual agency, tools for the interrogation of data (Corner 1999).

\section{OF MIXES: CREATIVE CLUSTERING IN MELBOURNE AND SYDNEY}

\section{Metropolitan-scale creative clustering}

To determine how and where creative industries are distributed across Melbourne and Sydney, the locations of individual activities were collected from a range of sources and plotted using GIS (Figure 1). ${ }^{3}$ In both cases, creative industries tend to locate in a range of inner city neighbourhoods; there is significant activity in the central city, but the most intensive clusters are immediately adjacent to the respective CADS, in Fitzroy/Collingwood (Melbourne) and Surry Hills (Sydney). These two clusters form the focus of this paper.
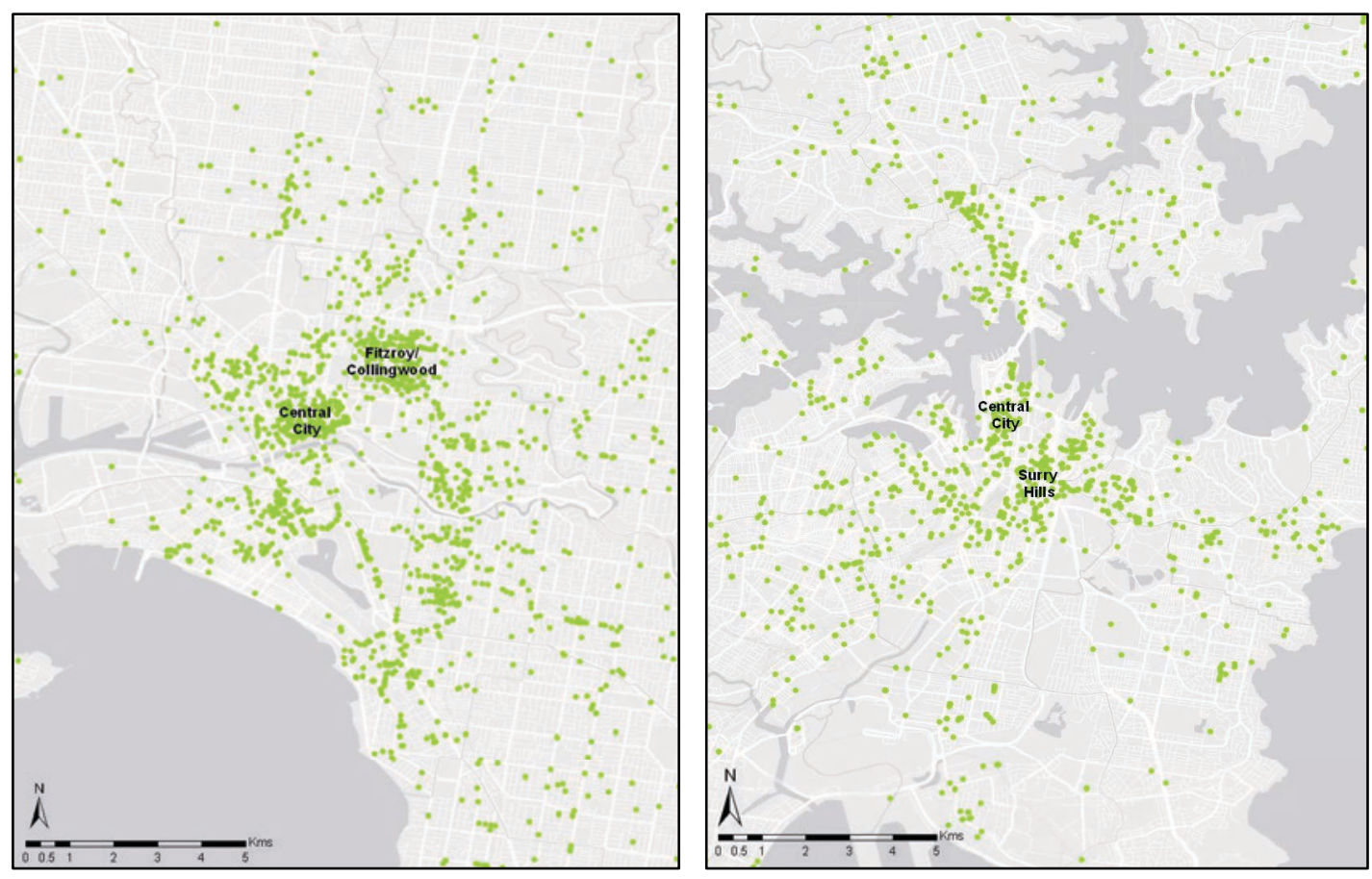

Figure 1: Locations of creative clusters in Melbourne (left) and Sydney (right), 2009.

Some key similarities and differences between these two cases may be immediately noted. Both were originally settled in the mid- $19^{\text {th }}$ Century as working-class neighbourhoods with a mix of residential and industrial as primary functions. Both were regarded as 'slums' by the early $20^{\text {th }}$ Century and were subject to major public housing projects in the mid-20 $20^{\text {th }}$ Century. Though the housing estates remain (Figure 2), both areas are now gentrified, Surry Hills more so than Fitzroy/Collingwood. Both are 
strongly integrated with metropolitan transport networks, offering high levels of access into the central city and around the greater metropolitan area. Both are framed by major arterial roads with feeders into the freeway system and well serviced by public transport. In both cases the neighbourhoods contained by these major streets are relatively protected from through traffic with a complicated system of one-way streets and barriers to deter rat-running. While some arterial roads and main streets penetrate these clusters they are often sufficiently jammed with traffic that speeds are low and pedestrian crossing is easy. The street networks are highly permeable with blocks of greater than 100 metres relatively rare; there is very little traffic in the smaller streets of both places and people commonly walk in the middle of the road. These neighbourhoods are at once connected yet protected. Surry Hills has a more variegated topography and a more informal street grid; bicycles are a major form of transport in flat Fitzroy/Collingwood but not in Surry Hills. A range of arts and innovation related institutions exist within, or close to, each of the two clusters (Figure 2). In each case two major universities are within walking distance (Melbourne and RMIT; Sydney and UTS) and there are a range of smaller university and arts institutions within or nearby. The street art and graffiti scene flourishes in Fitzroy/Collingwood (Dovey et al 2012) but is relatively muted in Surry Hills. To better understand the nature of these clusters, detailed mapping of both areas was conducted using three primary lenses: creative activities; functional mix; and urban morphology. In the following sections, each of these will be addressed in turn.

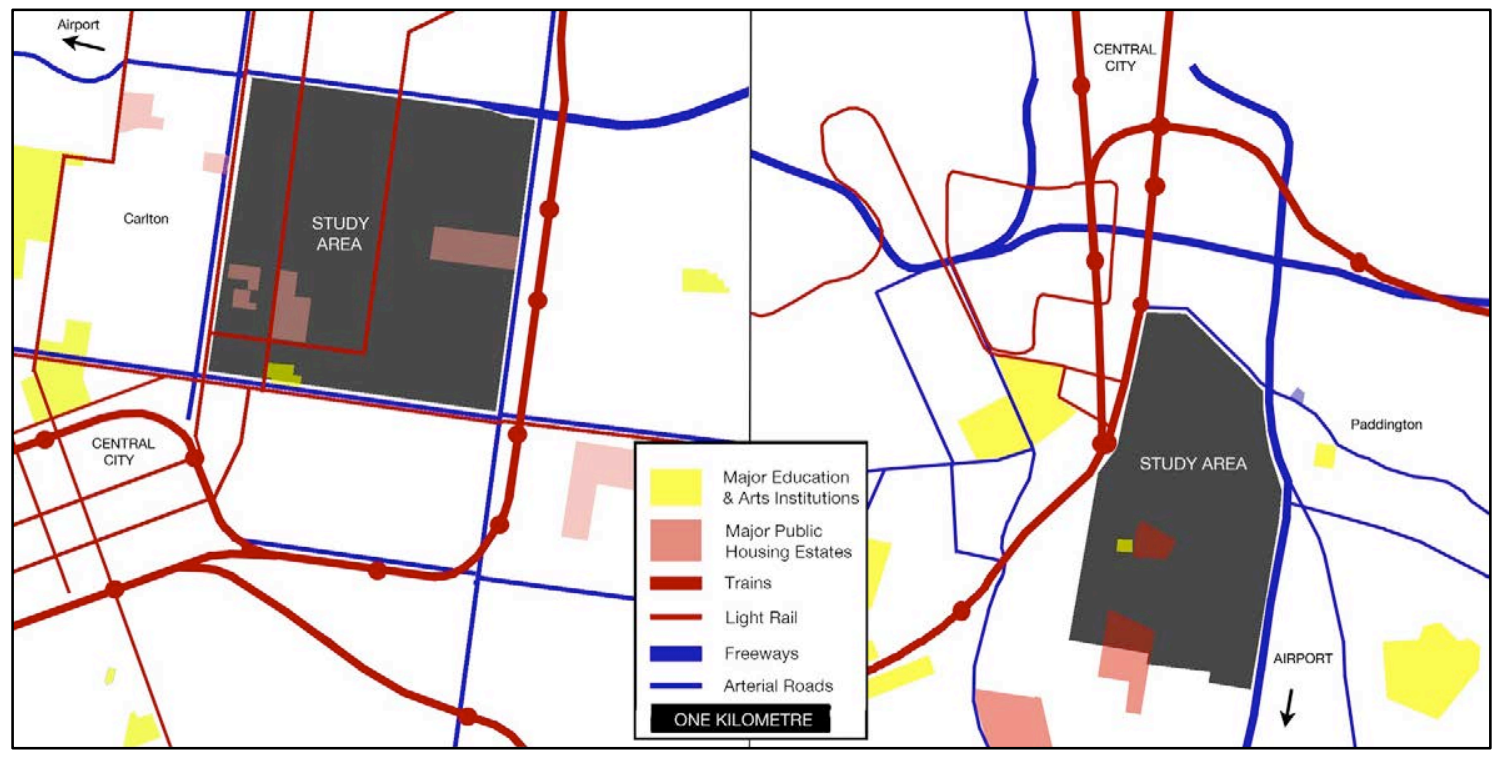

Figure 2: Case studies: Fitzroy/Collingwood, Melbourne (left) and Surry Hills, Sydney (right)

\section{Creative clustering in Fitzroy/Collingwood and Surry Hills}

For both cases, locations of creative activities were identified through land-use surveys. To analyse connections between these activities, we developed what might be termed walkable intensity maps or WIMs - where a straight line joins any sites within 400 metres of one another, roughly walking distance. Thus, clusters were represented by the roughly walkable interconnections between activities - 400 metres as the crow flies. While pedestrians are not crows, in these highly permeable neighbourhoods this is a loose correlate for 500 metre or five minute walkability - what is at stake here is a visual understanding of spatial clustering rather than exactitude. These are maps of potential (rather than actual) face-to-face contact, of the intensity of spatial clustering at the walkable scale, of potential accessibility. Where lines are predominantly short and overlap densely, the intensity of potential, walkable connections within the cluster is strong; where lines are long and overlap minimally, the intensity of the cluster is weaker.

Figure 3 depicts the location of different types of creative activities In Fitzroy/Collingwood and Surry Hills, along with WIMs showing potential walkable connections between all activities. In both cases we find that creative activities are relatively distributed - the cluster is a cluster of clusters and main street alignments. The WIMs show that in each case there are two separately walkable clusters - somewhat 
more dispersed and less intense in Melbourne than in Sydney. In both cases, there are 'holes' associated with public housing estates.
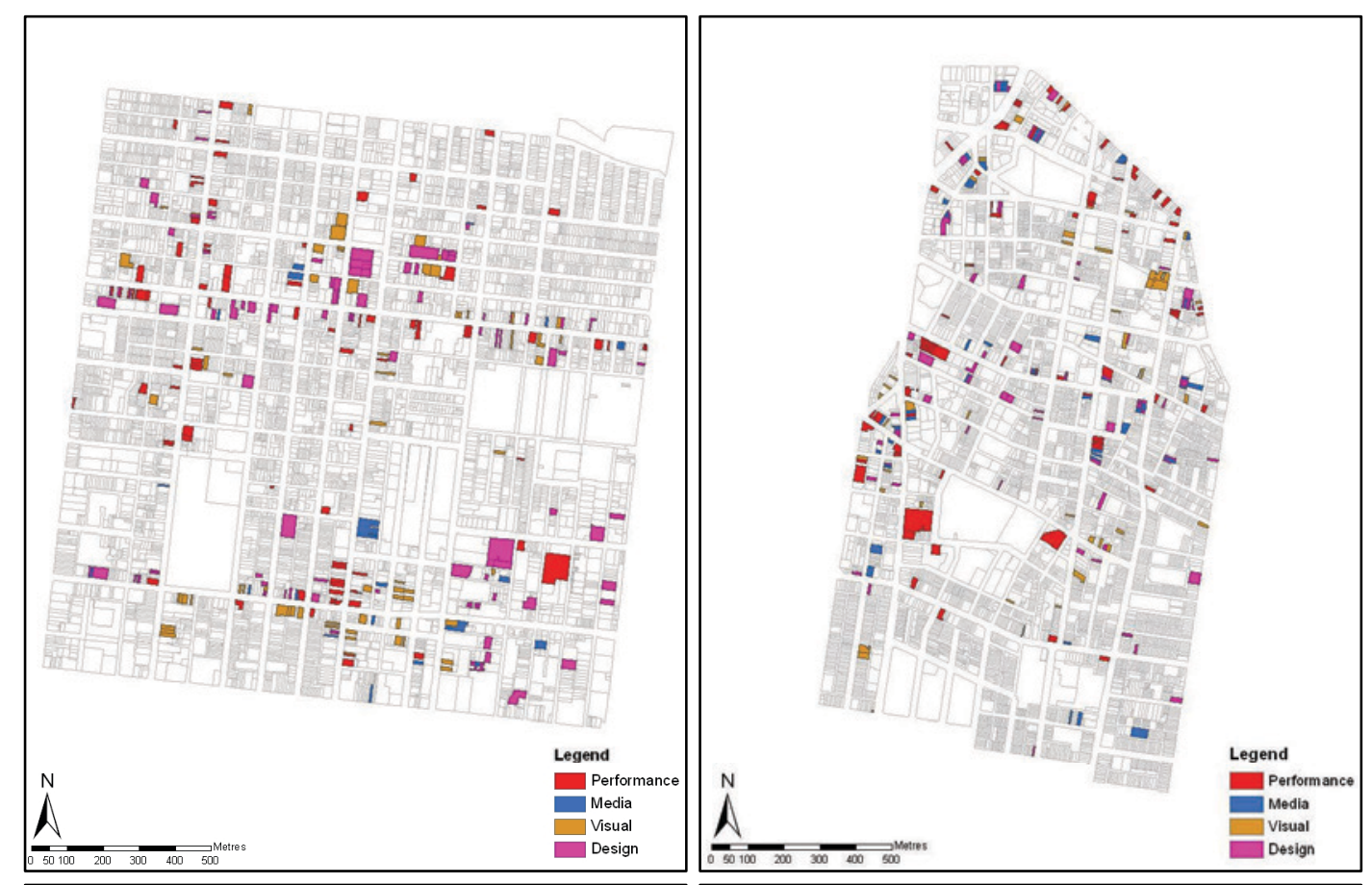

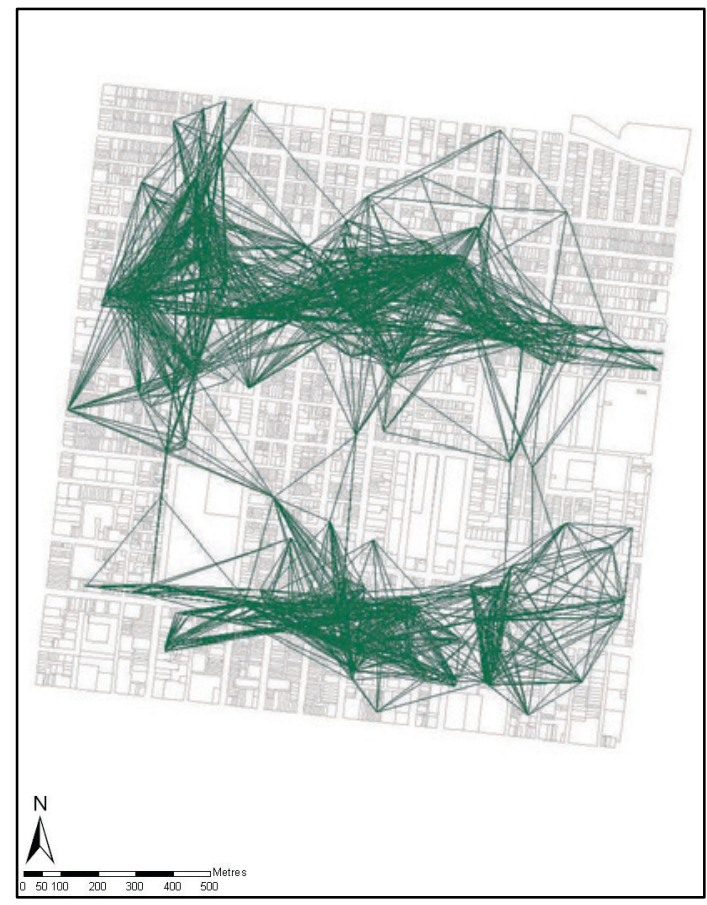

Fitzroy/Collingwood

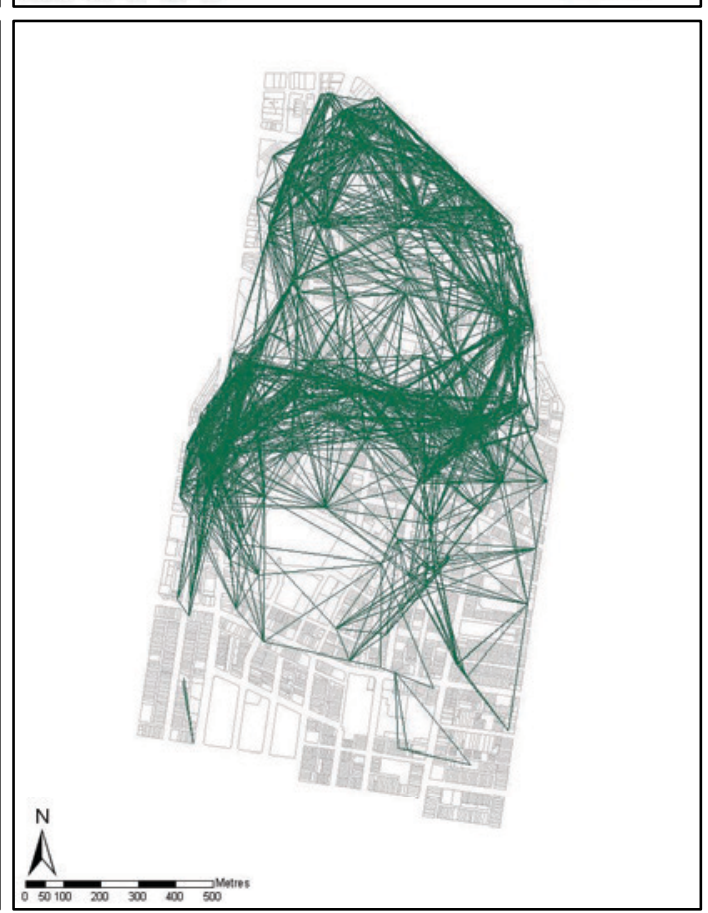

Surry Hills

Figure 3: Creative Clusters (above) and Walkable Intensity Maps (below)

To unpack this further, Figure 4 shows potential interconnections within each category of creative industry - design, visual arts, performance and media. Some key differences and similarities between the cases become obvious: Fitzroy/Collingwood has a greater proportion of design and Surry Hills has a greater proportion of media. In both cases, different types of creative activity tend to cluster in particular areas, occupying distinct yet (partially) overlapping territories. There are strong overlaps between design and media (both commercial functions). The most intense clustering of performance 
(music on main streets) occurs where design/media is less intense. In both cases visual arts activity (primarily galleries) is in multiple clusters with few clear overlaps.
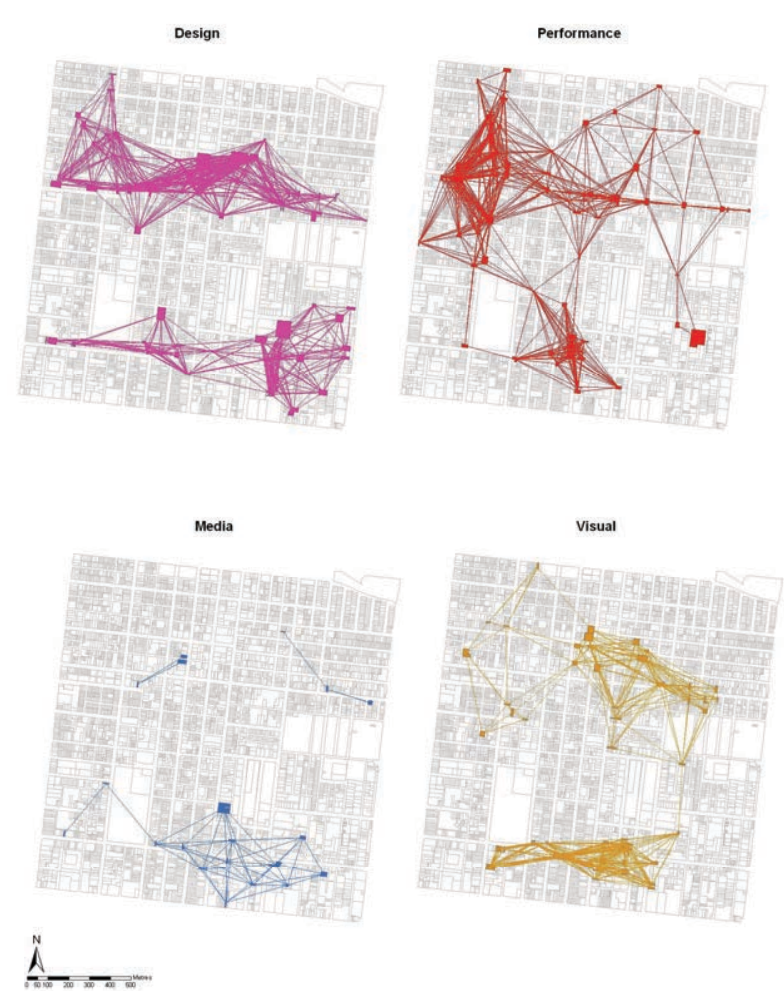
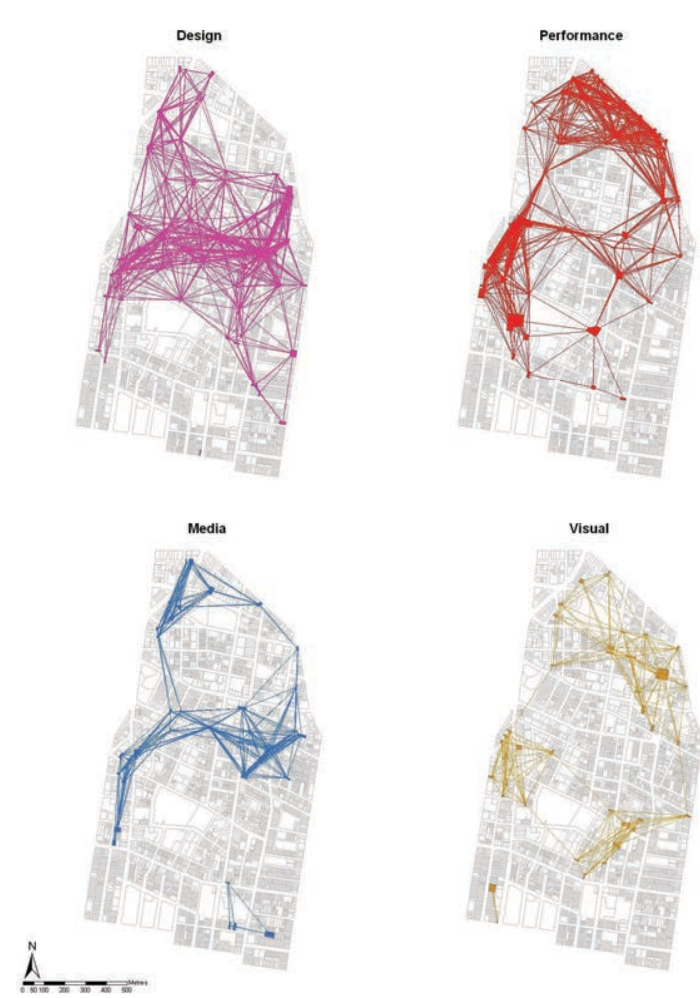

Surry Hills

Figure 4: Walkable Intensity Maps (WIMs) by Creative Industry

\section{Functional mix in Fitzroy/Collingwood and Surry Hills}

Functions were mapped according to the categories of: commercial (office), retail (exchange), hospitality (food and drink consumed on site), public services, industrial (production), residential and vacant/carpark (Figure 5). It was determined that seven categories is a maximum for readable maps. Ground and upper floor functions were mapped separately. While there are certain differences between the cases, the proportion of lots and land in each category is remarkably similar (Table 1). In both cases, around half of the land area is devoted to residential uses, accounting for between 60$70 \%$ of all lots. The key difference is that Surry Hills has largely lost the industrial production (brown) that still persists in Fitzroy/Collingwood. As a general rule, creative clustering is most intense in those areas that are functionally most mixed. Design and media activities are congruent with commercial space while music is congruent with hospitality. While design and visual arts do not compete for space with hospitality they are strongly interconnected. Hospitality is a kind of social glue in these sticky places. They are not simple clusters but distributed sets of forces - a network of clusters with holes in them. 


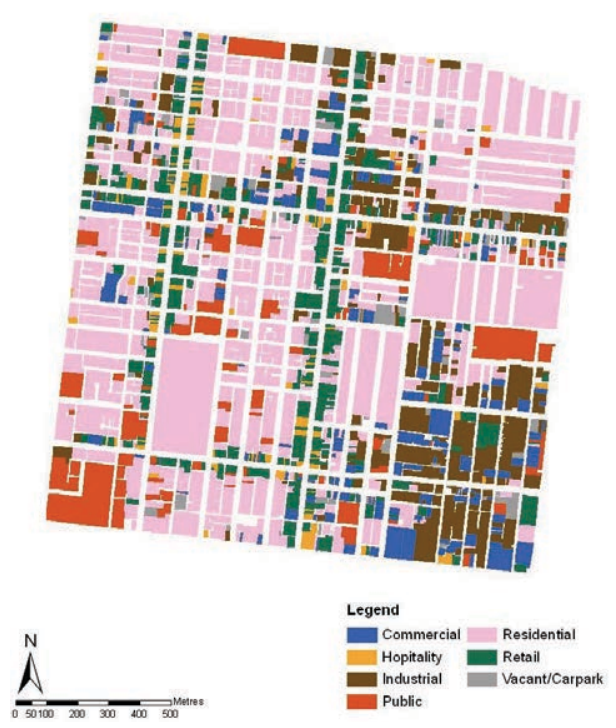

Fitzroy/Collingwood



Surry Hills

Figure 5: Ground floor Functional Mix

\begin{tabular}{|c|c|c|}
\hline & $\begin{array}{c}\text { Fitzroy/ } \\
\text { Collingwood }\end{array}$ & Surry Hills \\
\hline & \multicolumn{2}{|c|}{$\%$ of lots (\% of total area) } \\
\hline \multicolumn{3}{|l|}{ Function } \\
\hline Commercial & $5(7)$ & $6(6)$ \\
\hline Hospitality & $3(2)$ & $6(7)$ \\
\hline Industrial & $9(13)$ & $1(2)$ \\
\hline Public & $5(12)$ & $3(10)$ \\
\hline Residential & $63(51)$ & $70(56)$ \\
\hline Retail & $12(12)$ & $11(15)$ \\
\hline Vacant/car parking & $3(3)$ & $3(4)$ \\
\hline \multicolumn{3}{|l|}{ Grain Size $\left(\mathrm{m}^{2}\right)$} \\
\hline $0-250$ & $69(28)$ & $86(46)$ \\
\hline $251-500$ & $19(19)$ & $8(12)$ \\
\hline $501-1000$ & $7(15)$ & $4(12)$ \\
\hline $1001-2000$ & $3(10)$ & $1(9)$ \\
\hline $2001+$ & $2(28)$ & $1(21)$ \\
\hline \multicolumn{3}{|l|}{ Age } \\
\hline 19th Century & \multicolumn{2}{|c|}{$45(30)$} \\
\hline Early-20 th $\mathrm{C}$ & \multicolumn{2}{|c|}{$24(24)$} \\
\hline Post-WWII & $31(46)$ & $82(56)$ \\
\hline Height & & $9(12)$ \\
\hline $1-2$ & $90(74)$ & $9(32)$ \\
\hline $3-4$ & \multicolumn{2}{|c|}{$9(20)$} \\
\hline $5+$ & $1(6)$ & $84(61)$ \\
\hline
\end{tabular}

Table 1: Functional and morphological data. 
Finer-grained analysis of consumption-oriented functions suggests each area services three overlapping socio-spatial formations, here dubbed 'bohemia', 'gentrification' and 'welfare'. Bohemia is the generic term for primarily young, counter-cultural, students, artists, and creative sub-cultures. It manifests spatially in a mix of music and clothing stores, pubs and clubs, cheap restaurants and cafes, graffiti, second-hand and pawn shops, start-up galleries, cheap jewellery, street markets and some welfare services (youth services, drugs and health services). In many of the same locations are constellations of goods and services oriented to gentrifiers, drawing on the infusion of moneyed classes, professionals, and DINKs (Double Income No Kids). Typically housed in expensively renovated properties, these groups utilise upmarket restaurants, cafes, boutiques, galleries, designer furniture and homeware stores, renovation materials (tiles, rugs, paint), body care and selfimprovement (hair, health, psychology), and bars. Interlaced with the former socio-spatial formation are a range of welfare-oriented services, stemming in no small part from the major public housing estates incorporated into both sites (Figure 2). While such estates would appear to be separated enclaves, the disadvantaged communities they house are clients for an array of social services spread across the broader community. This is supplemented by a further range of down-market stores, pawnshops, second-hand and discount stores and soup kitchens. These three socio-spatial networks overlap not just as layers on the same urban fabric, but through certain synergies: bohemia and welfare share the down-market stores and services while bohemia supplies much of the labour and product for gentrified hospitality and design.

\section{Urban morphology of Fitzroy/Collingwood and Surry Hills}

The dimensions of urban morphology mapped were lot size, building age, building height and public/private interface type (Figures $6 \& 7$ ). These categories are partly based in theory, especially Jacobs (1961), and partly emerged during the study. Lot sizes were mapped on an exponential scale: $0-250 \mathrm{~m}^{2}, 251-500 \mathrm{~m}^{2}, 501-1000 \mathrm{~m}^{2}, 1001-2000 \mathrm{~m}^{2}$ and $>2000 \mathrm{~m}^{2}$ (Figures 6 \& 7). The morphologies of both sites embody a mix of small, mid-size and large grain lot sizes, though smaller grain-sizes predominate both in terms of areas and numbers (Table 1). All types of creative industries are found in small grain lots and there is a decline in creative production as grain size increases. In Melbourne, there is a tendency for music venues to occupy mid-sized lots $\left(251-500 \mathrm{~m}^{2}\right.$, while more than a quarter of design industries occupy larger lots $\left(>500 \mathrm{~m}^{2}\right)$; these tendencies are not apparent in Sydney.

Building ages were derived from building styles, and mapped according to three broad categories of $19^{\text {th }}$ century, early $20^{\text {th }}$ century and post- 1945 construction. In both case studies, $19^{\text {th }}$ century buildings are the most common, especially in Surry Hills. The urban fabric of both sites was built in many stages at many different times, with a mixed and layered urban character. All categories of creative activity are found in buildings of all ages, with few biases towards any category. Table 1 reveals that these differences in building ages are linked to differences in grain size: on average, $19^{\text {th }}$ century buildings occupy much smaller lots than $20^{\text {th }}$ century buildings (thus, although $82 \%$ of buildings in Surry Hills were constructed prior to 1901, they only account for $46 \%$ of the site in terms of area).

Building heights were mapped in three categories (Figures $6 \&$ 7), revealing that the vast majority of buildings are less than five storeys, and most of those fall in the 1-2 storey range. There is generally a greater density in Surry Hills than Fitzroy/Collingwood especially along the edge of the central city. Of the different creative industries, design and media are the most likely to be located in buildings over four storeys. Building height is a rough measure of density which is often flagged as a key threshold criterion for creative clustering. While those parts of these sites with uniformly low buildings tend not to be intensive clusters, there is no evidence of creative activities being congruent with higher density. Part of the issue here lies in the fact that taller buildings tend to produce a different public/private interface. 



Figure 6: Urban morphology of Fitzroy/Collingwood. 

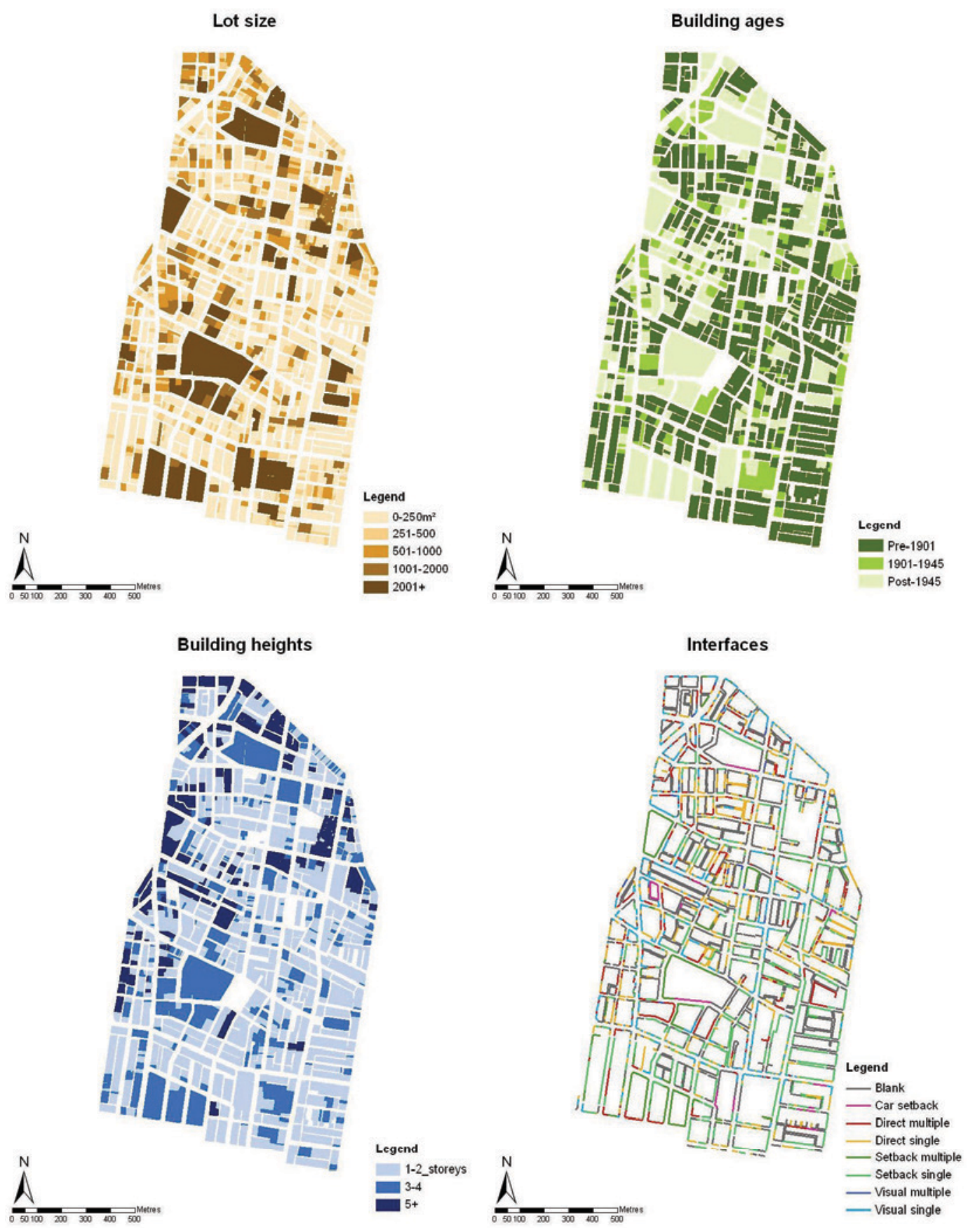

Figure 7: Urban morphology of Surry Hills, Sydney.

The final map in Figures 6 and 7 categorises public/private interfaces according to properties of permeability (to pedestrians), transparency (from the public gaze), setback (behind semi-private space) and car versus pedestrian access. This is a very complex yet significant issue since it is fundamental for practices of production, exchange, consumption and reproduction (Dovey \& Wood 2011). The key point to make here is that both sites have a highly variegated mix of interface types including high proportions of blank walls (laneways, post-industrial building types), pedestrian setbacks (row housing) and direct shopfronts. This interface morphology is quite unlike either a central city or a suburb, each of which is likely to be much more homogenous. This is also the most difficult of morphologies to map, a task plagued by ambiguities and hybrids. It is also worth noting the relative absence of certain interface types, particularly what we term the car setback (pedestrian entry via car parking) and secondary interface systems (primarily private shopping malls). 




Figure 8: Intensive and Weak clusters at 16 hectare scale

In order to understand these clusters better we now zoom to a scale of 400 metres square (16 hectares). Like the WIMs, this scale is again based on the idea of a walkable assemblage. Walkability is generally mapped as a walkable range centred on a particular site with a proximate zone of about 500 metres. Our approach is to focus on two-way flows between multiple attractions, whether houses, shops, work places, public transport or public spaces. At 16 hectares, every attraction within the frame is within 500 metres of every other attraction; these maps frame the multiplicity of two-way flows of desire that comprise the urban assemblage. The method in what follows is to select the 400 metres squares that contain the most intensive clusters of cultural production in each site (Brunswick and Johnston Streets in Fitzroy; Kippax Street in Surry Hills). We then contrast these with the parts of each site that have the least cultural production in the frame (Figure 8). 
Within the frames that contain the most intense clusters of creative activity we also find a high degree of mix for built environment variables. For each type of data that was gathered - age, grain-size, heights, public/private interfaces, functions - we find almost all categories represented. The situation is generally very different for those parts of Fitzroy/Collingwood and Surry Hills where there is little or no creative activity. In terms of grain size, Fitzroy/Collingwood almost entirely comprises a small grain; the Surry Hills frame contains large and small grain, but segregated rather than mixed. In both cases, buildings of the same age tend to cluster more (i.e. there is less age mix). The functional mix also differs substantially; for the most intense clusters it comprises a mix, with residential and retail uses predominating, followed by hospitality; in the blank areas it is mono-functional or lacks range, almost exclusively residential (Fitzroy/Collingwood) or mainly residential, supplemented by some retail and hospitality (Surry Hills).

\section{DISCUSSION}

The formal, functional and social mixes that characterise each of these case studies are difficult to define clearly, to pin down precisely. As with concepts such as 'buzz', 'atmosphere' and 'look and feel', it is difficult to say what a mix 'is' and any characterisation is liable to change with shifts in scale. These cases exhibit not just one mix - whether a mix of functions, grain sizes, building ages or interfaces - but a mix of mixes. It is difficult to explain why any particular characteristics of these places might matter - there are no clear cause/effect relations. We want to distinguish here between the various kinds of mix that we are arguing for (grain, age, function and interface) and the more particular ingredients into which we have divided them for purposes of mapping. What appears to matter is not only the mix of ingredients, but also synergies between different kinds of mix and lateral connections between particular ingredients. Just as agglomeration economics relies on spillover effects, both within and between industries, so creative clustering relies on connections and spillovers between morphological, functional and socio-economic diversities.

Despite the analytical challenges, the particular mix (of mixes) in these cases appears significant in terms of enabling and nurturing creative activities. There is a certain resilience of these creative clusters. In each case, neighbouring suburbs can be identified where creative cultural practices and industries once clustered yet no longer thrive in the same ways (Figure 2). Carlton, immediately adjacent to Fitzroy was a key cluster of creative life in Melbourne in the 1960s and 1970s - it remains vibrant but very heavily gentrified with boutiques, bistros and specialist food shops - only a couple of remnant theatres remain. Likewise, Paddington, adjacent to Surry Hills, was once more mixed but now specialises in galleries - the consumption end of just one creative art. Such withering of creative activity is surely linked to gentrification - the displacement of key marginal uses and lower socioeconomic classes, depleting both functional and social mixes (Catungal et al 2009; Barnes \& Hutton 2007; Miles 2004). Fitzroy/Collingwood and Surry Hills have also been subject to sustained gentrifying pressures but have been resilient to transformational change. Some key differences in each case are that the resilient clusters have substantial public housing estates, greater prevalence of post-industrial building stock of medium grain-size, and more relaxed heritage codes - issues to which we shall return. This resilience also seems related to the fact that certain key slow variables that threaten creative clustering have been relatively contained. Most prominent among them are building height, traffic flows and privatisation. 


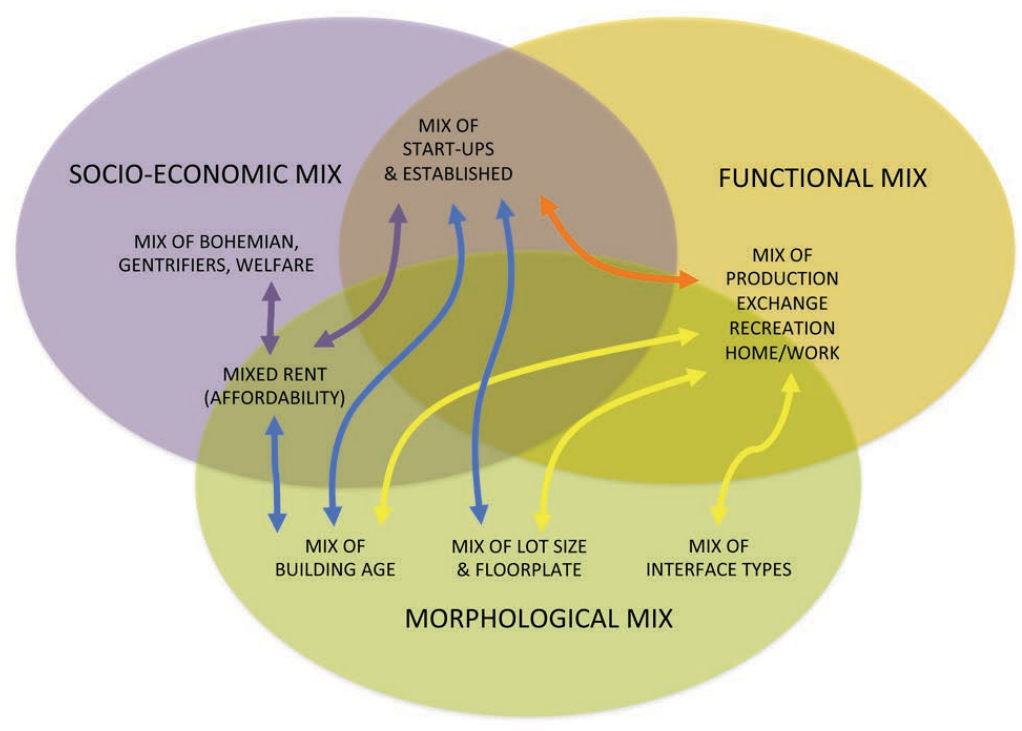

Figure 9: A mix of mixes

As is clear visually in the figures, and numerically in table, there are striking similarities in patterns of functional and spatial diversity between these two sites. Figure 9 is a diagram of some primary connections within this mix of mixes showing an intersection of socio-economic, functional and morphological mixes. The socio-economic mix incorporates a mix of social classes, cultural values, rental values and profitability; the functional mix incorporates a mix of production, exchange, consumption, residential and recreational uses; the morphological mix incorporates a mix of lot-sizes, building age and interfaces. The arrows in this diagram are the primary connections between different forms of mix. In what follows, the main task is to tease out the ways that different forms of morphological mix contribute to the functional mix (blue arrows) and socio-economic mix (yellow arrows).

\section{Mix of Grain Size}

Connections between grain or lot size and diversity are well established in the literature. Small grain sizes encourage diversity of ownership, occupancy and function, and build inertia because the time and effort to achieve site amalgamations make large grain development costly and difficult. Small grain flows through to affect vitality and street-life since a diversity of functions attracts a diversity of people at different times of the day and week, ensuring that "so many people are so close together, and among them contain so many different tastes, skills, needs, supplies, and bees in their bonnets' (Jacobs, 1961, p. 147). It is the intersections of these 'bees in bonnets' that primarily creates the 'buzz' of the creative clusters. Small lots tend to constrain building heights, producing environments that are intimately scaled, keeping life close to the street. By contrast, concentrations of large lots reduce diversity of ownership, occupancy and function, and are frequently associated with monotonous streetscapes, minimal street-life, and fragmented environments.

Yet small grain, by itself, produces only one kind of diversity, confined to similar sized enterprises. A mix of grain sizes enables a synergy between larger and smaller scales of production and consumption, each scale reciprocally attracting and drawing upon the other. Larger lots often enable small grain subdivisions with a flexibility that is lacking in small lots. The practice of sub-letting widespread in large floorplate buildings - provides opportunities for start-up enterprises to defray costs, to pool resources, and to expand and contract easily. The degrees and kinds of spatial segmentarity are supple and adaptable. The grain size of buildings that facilitate such arrangements can be regarded as hybrid in the sense that formal ownership and rental are controlled at the large grain level, while functional mix is small grain. Such buildings often house an intense mix of disparate functions and tenants in close proximity, enabling happenstance to forge cross-pollination and collaboration. Finally, a mix of lot-sizes for residential functions can go some way towards countering 
the homogenizing effects of gentrification. Large dwellings with multiple rooms may enable sharehouseholds to pool finances and outbid single-family households in the private rental market; very small lots may prove resistant to gentrification because renovation potential is limited.

\section{Mix of Building Age and Type}

Each case study, originally developed with a mix of industrial, residential and retail building types, has a layered urban fabric that has developed over multiple eras. The staging of development and the mix of layers has produced an irregular morphology that cannot be regulated on the basis of consistency. No historical line can be easily drawn in the sand to declare the neighbourhood 'finished' and this works to ensure that the built-environment remains open to creative adaptation. Both neighbourhoods are now developed under heritage codes that enable yet constrain new development - largely preventing demolition and transformational change yet enabling infill. Older buildings give a place a temporal narrative and character but they only do this when the city is layered over time, where development is relatively continuous. A strong heritage code brings the danger of museumisation, constructing an illusion of living in an earlier time. The issue of heritage works both for and against creative clustering - adding a sense of authentic history yet stopping innovation and increased density.

The many old buildings in the cases are important for a range of reasons: for their heritage value, for their low rents based on dilapidation and obsolescence, and for their flexible spatial designs. A mix of old and new produces both high rent (new) and low rent (dilapidated) conditions in the same neighbourhood (Jacobs 1961). New buildings require high levels of investment and primarily service the most profitable end of the market. Retaining old buildings works to retain a mix of building types by preserving those that are not currently profitable. The value of older buildings also links to the factory and warehouse morphology of industrial heritage which produces large floorplates, often without the parking, views or high costs.

The tendency for heritage controls to prevent ever-increasing building height has both positive and negative effects on creative clustering. Taller buildings primarily contribute through density, producing more street life volume and intensity. Yet they also produce more blank street frontages, traffic, shadows and black holes for car parks entrances. Every tall building tends to become a monofunctional cul-de-sac in the urban fabric, reducing the mix and distancing its inhabitants from the rich face-to-face network of the street. The relative rarity of tall buildings means that most streetscapes have high levels of sunshine and streetscape liveability, and disconnection between building inhabitants and the street is minimised. This condition of being on the edge of urban life rather than gazing down on it is also linked to the geographic context adjacent to the central city. These are edgy places identified as other to the central city, highly accessible but not suited to the suits. While remaining reliant on global markets, corporate culture is held at arm's length. While corporate towers loom in the adjacent city, the relative absence of building height in both cases works to reduce the corporate-culture feel. Street network characteristics combine with heritage protection to generate the experience of a walkable urban village: integration with the broader city makes it urban; the protected, permeable streets make it liveable and walkable.

\section{Mix of Public/Private Interfaces}

The mix of building types is also linked to a mix of public/private interface types - based on variables of transparency, setback and permeability - which in turn service a mix of functions. As the maps in Figures 6-8 show these sites have a relatively high level of interface diversity, compared to other neighbourhood districts in Australian cities. The suburb, the shopping strip, the central city and the shopping mall generally have a much more homogenous interface type. In many such locations, planning codes also operate to prevent the adaptation of one type to another. By contrast, in both cases a relatively high level of adaptation between interface types was found, particularly as those originally related to industrial production become adapted to commercial, residential and exchange functions. We suggest that these interface adaptations are an important mode of innovation in urban design where an underlying potential becomes actualized; new connections are formed between production, exchange and consumption; new forms of urban intensification become possible. Such 
interface adaptation is reliant on a rich mix of interface types and relaxed governance with regard to setback and function (Dovey \& Wood 2011).

\section{Mix of Functions}

In key respects, functional mix is enabled or constrained by morphology. With respect to interface types, for example, while retail and hospitality functions generally require a direct and transparent connection to passing trade, commercial and industrial functions often require stricter mediation of access, and residential prefers a setback. In this context, it is no accident that music venues and art galleries tend to cluster in close proximity to retail and hospitality functions; symbiotic relationships exist, along with a shared need to be oriented to sidewalks. Likewise, design, media, commercial and industrial functions also tend to be clustered; having no need to capture passing trade, they have no pressing need to pay premium rents associated with street frontage premises. Thus a mix of land uses facilitates symbiotic relationships between different creative activities, and between creative activities and other functions. It also links to a diversity of built forms that in turn link to the diversity of locational preferences amongst different creative activities, enabling a mix of creative activities to coexist in the one suburb.

\section{Socio-Economic Mix}

It was suggested earlier that the social mix in these clusters might be characterised as three overlapping groups of youth/bohemians, welfare and gentrifiers. These groups mix, overlap, interpenetrate, hybridise, intersect and cross-infect, both socially and spatially, producing tensions and synergies. Welfare and bohemia have overlaps in terms of health and housing services; welfare functions as a brake on rents and gentrification, increasing housing opportunities for bohemia. There is a synergy between gentrifiers and bohemians because they form the major/minor, established/startup, dominant/subculture and employer/employee linkages of the creative cluster. Gentrification displaces youth/bohemians who often become gentrifiers over time. These three cultures do not, of course, account for all the people and places within these case studies. Nevertheless, it is within a mix of this kind that creative cultures and industries find a home, drawing labour from both gentrifiers and youth/bohemians. The public housing estates in each of the case studies contribute to creative clustering in terms of social mix and as a brake on gentrification. The morphology of public housing estates - a large-scale segmentation of the city into class-based enclaves with secondary interface systems - is seriously disruptive to all of the morphological characteristics found to be important in this study. While these estates can be observed on the maps as holes in the creative clustering their role may be more central than it seems.

While we have highlighted the seminal work of Jacobs, another precedent of note here is the intriguing concept of 'porosity' as introduced by Benjamin and Lacis in their 1924 description of the slums of Naples (Benjamin 1996). Never clearly developed by Benjamin and often conflated in the literature with spatial 'permeability', porosity is a broader concept that valorizes urban interpenetrations of public/private space, community/family, construction/dilapidation and festival/everyday:

Building and action interpenetrate in the courtyards, arcades and stairways. In everything, they preserve the scope to become a theatre of new, unforeseen constellations. The stamp of the definitive is avoided. No situation appears intended forever, no figure asserts its "thus and not otherwise"... Porosity results... above all, from the passion for improvisation, which demands that space and opportunity be preserved at any price. (Benjamin 1996: 416)

Such a parallel between the slum and the creative cluster can only be taken so far but it is notable that our two case studies are both former slums and retain elements of relative poverty. What we have mapped and construed above as a mix of mixes can be seen in terms of multiple interpenetrations that are at once spatial, temporal and social. Benjamin and Lacis add that 'the true laboratories of this great process of intermingling are the cafes' (Benjamin 1996: 421); in our cases we would add the post-industrial buildings as laboratories together with key ingredients of small grain and bohemia. 
In terms of assemblage theory the mix of mixes outlined here is known as a 'multiplicity' and linked to the philosophical project to establish the primacy of difference over identity. From such a view the creative cluster is not a totality that can be mobilised and reproduced as creative city policy. Inasmuch as the creative cluster literature refers to qualities of place, it remains focused on the totality of the cluster effects (the 'buzz' or 'atmosphere') rather than the multiplicitous vectors. For Deleuze and Guattari (1987) multiplicities are the productive forces of assemblage. The flow of creative ideas is sparked within such multiplicities as a connection of two previously unrelated parts - the bi-sociation that Koestler (1964: 35-6) identifies as the essence of creativity. The synergies of creative production take flight under conditions of an intensive intersection of differences.

Deleuze and Guattari (1987: 33; also Deleuze 1988, drawing on Bergson), suggest two fundamental kinds of multiplicity - extensive and intensive. An 'extensive multiplicity' is where the constituent parts are defined by their spatial extension and are unaffected by new additions. No matter how many ingredients are added each ingredient retains its own flavour. An 'intensive multiplicity' by contrast is more like a soup with an overall flavour which is changed by each new ingredient as it enters into multiple relationships. While the maps we have produced have a static quality (akin to the extensive multiplicity), it is clear that a creative cluster is an intensive multiplicity. When different people, practices and built forms are added, the 'sense' of the larger place changes (Dovey 2010: Ch 2). From such a view what is labeled in the literature as 'buzz', 'flavour', 'feel', 'atmosphere', 'character' and so on are intensities produced by the multiplicity.

In Figure 9 these multiple relations are depicted as multi-directional arrows. While they are at times vectors (mixed age of buildings is productive of mixed rent) the double arrows represent an interdependency between them; they are mutually constitutive and reciprocal; the one is complicit with and implicit in the other. These 'pli' words foreground the idea of connection, as Deleuze argues rhetorically:

What is an assemblage? It is a multiplicity which is made up of many heterogeneous terms and which establishes liaisons, relations between them... Thus, the assemblage's only unity is that of co-functioning: it is symbiosis, a "sympathy". It is never filiations which are important, but alliances, alloys; these are not successions, lines of descent, but contagions, epidemics, the wind. (Deleuze and Parnet 1977, 69)

These interconnections are face-to-face 'liaisons', 'alliances' and 'symbioses' - reciprocal relations of mutual dependency and benefit. 'Sympathy' implies support, understanding and a common feeling. The 'alloy' suggests the emergence of new hybrid identities. 'Contagion' suggests the rhizomic spread of ideas; that creativity can be caught like a cold, there is something in the 'wind'. Deleuze is clear these are primarily relations of co-functioning rather than 'filial' relations of descent or causation; creative practices do not derive from these urban morphologies any more than the morphology derives from the creativity. To focus on the 'buzz', 'atmosphere' or 'character' is to describe the emergent effect or 'sense' of the place but it does not show how it works. "Don't ask what it means", says Deleuze, "ask how it works" (quoted in Buchanan \& Marks 2000). It works through the intensive co-functioning interconnections between different people, practices, identities, spaces and built forms. The creative cluster is a socio-spatial assemblage that gears capitalism to creative production; a place where cross-connections between differences become the norm; where the answer, as they say, is in the 'wind'.

\section{REFERENCES}

Banks, M. \& O'Connor, J. (2009). After the creative industries'. Int J of Cultural Policy, 15(4), 365-373. Barnes \& Hutton, T. (2009). Situating the New Economy: Contingencies of Regeneration and

Dislocation in Vancouver's Inner City. Urban Studies, 46(5/6), 1247-1269.

Bateson, G. (2000 [1972]) Steps to an Ecology of Mind University of Chicago Press 2000.

Benjamin, W. (1996) Selected Writings: Volume 1. Cambridge, Ma.: Harvard University Press.

Bell, D. \& Jayne, M. (2003). 'Design-Led' Urban Regeneration: A Critical Perspective. Local Economy, 18(2), 121-134.

Bohme, G. (1998). The Atmosphere of a City. Issues in Contemp Culture \& Aesthetics(7), 5-13. 
Bohme, G. (1993). Atmosphere as the Fundamental concept of a new Aesthetics. Thesis Eleven (36), 113-126.

Brown, J. and Meczynski, M (2009). 'Complexcities': Locational Choices of Creative Knowledge Workers. Built Environment, 35(2), 238-252.

Catungal, J. Leslie, D. \& Hi, Y. (2009). Geographies of Displacement in the Creative City. Urban Studies, 46(5/6), 1095-1114.

Chapain, C. and Comunian, C. (2009). Creative Cities in England: Researching Realities and Images. Built Environment, 35(2), 220-237.

Corner, J. (1999). The Agency of Mapping. In D. Cosgrove (Ed.), Mappings (pp. 213-252). London: Reaktion.

Currid, E. \& Williams, S. (2010). The geography of buzz: art, culture and the social milieu in Los Angeles and New York. J of Economic Geography, 10, 423-451.

Deleuze, G. (1988), Bergsonism. New York: Zone Books.

Deleuze, G. and Guattari, F. (1987), A Thousand Plateaus, London, Athlone.

Deleuze, G. \& Parnet, C. (2007). Dialogues II. New York: Columbia UP.

Dovey, K., Woodcock, I and Wood, S . (2009) 'A Test of Character: regulating place-identity in inner-city Melbourne', Urban Studies, 46 (12): 595-2615

Dovey, K. \& Wood, S. (2011) 'Public/Private Interfaces in the Inner City' Proceedings, State of Australian Cities, National Conference, Melbourne, http://soac2011.com.au/full-papers-list.php, $11 \mathrm{pp}$.

Dovey, K., Wollan, S. \& Woodcock, I. (2012) 'Placing Graffiti' Journal of Urban Design, 17 (1): 21-41.

Drake. (2003). 'This Place Gives me Space': Place and creativity in the creative industries. Geoforum, 34, 511-524.

Evans, G. (2003). Hard-Branding the Cultural City - From Prado to Prada. Int J of Urban \& Regional Research, 27(2), 417-440.

Evans, G. (2009). From cultural quarters to creative clusters - creative spaces in the new city economy. In M. Legner (Ed.), The sustainability and development of cultural quarters (pp. 3259). Stockholm: Institute of Urban History.

Evans, G. \& Foord, J. (2007). The Generation of Diversity. In: S. Porta et al. (Eds), Urban Sustainability Through Environmental Design. London: Taylor \& Francis.

Florida, R. (2002). The Rise of the Creative Class. New York: Basic Books.

Florida, R. (2005). Cities and the Creative Class. New York: Routledge.

Gertler, M. (2003). Tacit Knowledge and the Economic Geography of Context. J of Econ Geography, 3, 75-99.

Helbrecht, I. (2004). Bare Geographies in Knowledge Societies - Creative Cities as Text and Piece of Art:. Built Environment, 30(3), 194-203.

Ho, K. C. (2009). The Neighbourhood in the Creative Economy: Policy, Practice and Place in Singapore. Urban Studies, 46(5/6), 1187-1201.

Hutton, T. (2004). The New Economy of the Inner City. Cities, 21(2), 89-108.

Hutton, T. (2006). Spatiality, built form, and creative industry development in the inner city. E\&P A, 38, 1819-1841.

Hutton, T. (2009). Trajectories of the New Economy. Urban Studies, 46(5/6), 987-1001.

Indergaard, M. (2009). What to Make of New York's New Economy? The Politics of the Creative Field. Urban Studies, 46(5/6), 1063-1093.

Jacobs, J. (1961). The Death and Life of Great American Cities. Harmondsworth: Penguin.

Jacobs, J. (1969) The Economy of Cities, New York: Vintage.

Jacobs, J. (1985) Cities and the Wealth of Nations. New York: Vintage.

Katz, M. \& Shapiro, C. (1985) Network Externalities, Competition, and Compatibility. American Economic Review, 75:3, 424-40.

Koestler, A. (1964) The Act of Creation, London: Hutchinson

Liebowicz, S. \& Margolis, S. (1994) Network Externality. Journal of Economic Perspectives, 8 (2), 133150)

Lloyd, R. (2002). Neo-Bohemia: Art and Neighbourhood Redevelopment in Chicago. Journal of Urban Affairs, 24(5), 517-532.

Markussen, A. (1996). Sticky Places in Slippery Space. Economic Geography, 72, 293-313.

Miles, M. (2004). Drawn \& Quartered. In B. Jayne (Ed.), City of Quarters (pp. 37-55). Aldershot: Ashgate. 
Mommaas, H. (2004). Cultural Clusters and the Post-industrial City. Urban Studies, 41(3), 507-532. Newman, P. \& Smith, (2000). Cultural Production, Place and Politics on the South Bank of the Thames. International Journal of Urban and Regional Research, 24(1), 9-24.

Peck, J. (2005). Struggling with the Creative Class. Int J of Urban \& Regional Research, 29(4), 740770.

Rantisi, N. \& Leslie, D. (2006). Placing the creative economy. E\&PA, 38, 1789 -1797.

Storper, M., \& Venables, A. (2004). Buzz: Face to Face Contact and the Urban Economy. J of Economic Geography, 4(4), 351-370.

Trip, J. (2007). Assessing quality of place: a comparative analysis of Amsterdam and Rotterdam. Journal of Urban Affairs, 29 (5), 501-517.

\footnotetext{
${ }^{1}$ This work was funded in part by Australian Research Council Project DP0987867

${ }^{2}$ Initial attempts to discriminate between independent/subcultural activity and established/commercial proved unfruitful because these practices are too blurred to produce good data.

${ }^{3}$ Addresses for architects, landscape architects, graphic designers, furniture designers, advertising agencies and film production services were sourced from telephone directories; art galleries were primarily sourced from Art Almanac (a guide that lists most art galleries, Australia-wide); theatre and cinema were primarily sourced from listings in newspaper entertainment guides; and music venues were sourced from listings in newspaper entertainment guides, along with street press gig guides.
} 